\title{
Clonidine Hydrochloride in the Treatment of Hypertension
}

SIBLEY W. HOOBLER, MD, FACC

EDMUNDO SAGASTUME, MD

Ann Arbor, Michigan
From the Hypertension Section, Department of Internal Medicine, University of Michigan Medical Center, Ann Arbor, Mich. This study was assisted by U. S. Public Health Service Grant 5M01-FR-42 to the Clinical Research Unit, University of Michigan Medical Center, which enabled hospitalization of patients included in the study. Manuscript received December 14, 1970, accepted February 12, 1970.

Address for reprints: Sibley W. Hoobler, MD, Hypertension Section, R6669 Kresge Medical Research Building, University of Michigan Medical Center, Ann Arbor, Mich. 48104.
Clonidine hydrochloride (Catapres) combined with a diuretic agent was given to 57 patients for a period of 6 months to 2 years. It was. shown to be an effective agent for the long-term treatment of hypertension. It acts by central inhibition of adrenergic vasomotor stimulation; its withdrawal can cause transient sympathoadrenal hyperactivity. Dry mouth, constipation and transitory drowsiness were the most common side effects. They diminished with time, even when the dose was progressively increased. Bradycardia was produced by inhibition of cardiac sympathetic innervation, but no serious dysrhythmias occurred.

The drug can be used to advantage as a replacement for guanethidine or methyldopa (Aldomet) but must be given with a diuretic agent. Orthostatic hypotension was rare. Addition of hydralazine or reserpine in conventional dosage decreased blood pressure very moderately. No change was observed when alpha methyldopa was added. On the contrary, administration of clonidine to a patient exhibiting partial adrenergic blockade with guanethidine augmented the effects of such blockade, causing a further decline in both standing and recumbent blood pressure.

This 3 year experience shows that clonidine is safe and free from toxicity. It is effective if patiently administered in increasing dosage until proper control of blood pressure is achieved.

Clonidine hydrochloride (Catapres ${ }^{\circledR}$ ) is a new antihypertensive agent which apparently works to inhibit those central nervous system connections which ordinarily are active in increasing blood pressure. The hypotensive action of the drug is unique: it does not block adrenergic receptors like dibenzyline; it does not interfere with peripheral sympathetic nerve discharge as does bretylium or guanethidine; it is not a ganglionic blocking agent and it has no reserpine-like effect in depleting tissues of norepinephrine. It does act through the sympathetic nervous system since its depressor action is prevented by pretreatment with guanethidine.

For some time investigators had no good proof of its point of action until Kobinger ${ }^{1}$ showed its central depressor effect by injecting small doses into the cisterna magna of cats, and Sattler and Van Zwieten ${ }^{2}$ showed that a low dose given into the vertebral artery was likewise effective. Finally, Schmitt et al..$^{3}$ observed a marked decrease in splanchnic efferent neural discharge after intravenous injections of clonidine into the dog. It should be stressed that central nervous inhibition, not blockade, is achieved : that is, a strong enough stimulus can break through the inhibition with a resulting increase in blood pressure.

The hemodynamic effects of clonidine in man are similar to 
TABLE I

Effect on Blood Pressure of Substituting Placebo After Long-Term Clonidine Therapy*

\begin{tabular}{|c|c|c|c|c|}
\hline \multirow[b]{3}{*}{$\begin{array}{l}\text { Case } \\
\text { no. }\end{array}$} & \multicolumn{2}{|c|}{ Clonidine } & \multirow{2}{*}{\multicolumn{2}{|c|}{$\begin{array}{l}\text { Recumbent Blood Pressure } \\
\text { (mm Hg) }\end{array}$}} \\
\hline & \multirow{2}{*}{$\begin{array}{l}\text { Daily } \\
\text { Dose } \\
\text { (mg) }\end{array}$} & \multirow{2}{*}{$\begin{array}{l}\text { Length of } \\
\text { Therapy } \\
\text { (mo) }\end{array}$} & & \\
\hline & & & $\begin{array}{c}\text { On } \\
\text { Clonidine }\end{array}$ & $\begin{array}{l}\text { Off Clonidine } \\
\text { (12-24 hours) }\end{array}$ \\
\hline 1 & 0.50 & 7 & $160 / 110$ & $230 / 140$ \\
\hline \multirow[t]{2}{*}{2} & 0.30 & 1 & $168 / 92$ & $170 / 114$ \\
\hline & 0.45 & 9 & $130 / 84$ & $174 / 108$ \\
\hline 3 & 1.20 & 3 & $150 / 100$ & $200 / 130$ \\
\hline \multirow[t]{2}{*}{4} & 0.50 & 2 & $162 / 92$ & $200 / 140$ \\
\hline & 0.50 & 14 & $188 / 102$ & $252 / 132$ \\
\hline 5 & 0.60 & 12 & $170 / 126$ & $220 / 140$ \\
\hline 6 & 0.375 & 3 & $144 / 90$ & $170 / 100$ \\
\hline 7 & 0.90 & 10 & $240 / 130$ & $270 / 130$ \\
\hline 8 & 0.675 & 2 & $166 / 94$ & $214 / 142$ \\
\hline
\end{tabular}

* During placebo substitution background diuretic therapy was not changed.

those seen when other drugs are given to reduce sympathetic outflow, namely, an initial decline in both cardiac output and total peripheral resistance. ${ }^{4}$ Some unusual characteristics have been reported in animal and human studies. The first effect of intravenous administration is a transient increase in blood pressure $e^{5,6}$ corresponding to a transient stimulation of alpha receptors. ${ }^{7}$ This is not seen when the drug is given orally. During the later phase of reduction of blood pressure the changes in peripheral resistance correspond to those expected of a sympathetic inhibitor except for a decrease in muscle vascular resistance and enhanced vasoconstriction in the skin.5,6 In this and other respects, the drug appears to act in a contrary fashion to tolazoline (Priscoline ${ }^{\circledR}$ ), and the close chemical similarity explains the fact that tolazoline is a specific antidote to the action of clonidine, when given in a ratio of $100: 1 .^{5}$

\section{Clinical Pharmacology}

Clonidine is a substituted imidazoline. The drug is readily absorbed by mouth and has an action span of 4 to 6 hours; therefore, it must be given 3 to 4 times daily for a sustained depressor effect. The average effective single oral dose is $0.2 \mathrm{mg}$. Amounts of the drug given are so small that it is difficult to follow its course in the body, but the best evidence to date suggests that it is excreted unchanged in the urine.

Clonidine also has effects unrelated to adrenergic blockade. These are presumably the result of direct action and are exactly as predicted for an antagonist to tolazoline. There are a decrease in salivation (the drug is also concentrated in the salivary gland) and a rather marked reduction in gastrointestinal secretion and motility which leads to constipation. The drug also produces transient drowsiness, although-as with alpha methyldopa - this effect wears off with the passage of time.

In summary, clonidine would be expected to lower pulse rate and decrease blood pressure by its sympathetic inhibitory action, yet because it inhibits rather than blocks the central reflex connections that control blood pressure, a sufficient pressor stimulus would break through. The most common such stimulus is the assumption of the upright posturc: after administration of clonidine the depressed blood pressure does not fall further in contrast with the postural hypotension seen after treatment with guanethidine.

As with other antihypertensive drugs, concomitant use of diuretic agents is necessary to sustain depressor effects 8 ; hence, in this study a diuretic agent was administered before and during treatment with clonidine.

\section{Method of Study}

We undertook the study of this drug at the University of Michigan Medical Center in the summer of 1967. After preliminary trials for effectiveness, we elected to

TABLE II

Initial and Final Effects of Clonidine in All Patients Followed Up 6 Months or More*

\begin{tabular}{|c|c|c|c|c|c|}
\hline \multirow{2}{*}{\multicolumn{2}{|c|}{$\begin{array}{c}\text { Prior } \\
\text { Treatment } \\
\text { (daily dose, } \\
\text { mg) }\end{array}$}} & \multicolumn{3}{|c|}{ Treatment with Clonidine } & \multirow[b]{2}{*}{$\begin{array}{c}\text { Blood } \\
\text { Pressure }\end{array}$} \\
\hline & & $\begin{array}{c}\text { Initial } \\
\text { Recumbent } \\
\text { Blood } \\
\text { Pressure } \\
\text { (mm Hg) }\end{array}$ & $\begin{array}{l}6 \text { Month } \\
\text { Recumbent } \\
\text { Blood } \\
\text { Pressure } \\
\text { (mm Hg) }\end{array}$ & $\begin{array}{l}6 \text { Month } \\
\text { Daily } \\
\text { Dose } \\
\text { (mg) }\end{array}$ & \\
\hline \multicolumn{2}{|c|}{ None† } & $153 / 107$ & $132 / 82$ & 0.1 & + \\
\hline & 0.50 & $166 / 122$ & $130 / 83$ & 0.3 & + \\
\hline & 500 & $191 / 113$ & $151 / 85$ & 0.4 & + \\
\hline & 500 & $185 / 120$ & $190 / 111$ & 0.8 & - \\
\hline$M$ & $.1,000$ & $205 / 110$ & $174 / 95$ & 2.4 & + \\
\hline M & 1,000 & $169 / 112$ & $148 / 96$ & 0.4 & + \\
\hline M & 1,500 & $216 / 116$ & $176 / 100$ & 3.0 & + \\
\hline M & 2,000 & $212 / 120$ & $185 / 116$ & 0.8 & - \\
\hline G & 25 & $209 / 120$ & $142 / 100$ & 0.4 & + \\
\hline G & 25 & $183 / 115$ & $168 / 114$ & 0.4 & - \\
\hline G & 30 & $238 / 133$ & $157 / 98$ & 1.2 & + \\
\hline $\mathbf{G}$ & 50 & $183 / 113$ & $130 / 84$ & 0.8 & + \\
\hline G & 50 & $186 / 116$ & $131 / 82$ & 0.3 & + \\
\hline G & 50 & $160 / 120$ & $165 / 117$ & 1.2 & - \\
\hline \multirow[t]{2}{*}{ G } & $75-100$ & $250 / 180$ & $209 / 143$ & 1.2 & + \\
\hline & Average & $194 / 121$ & $159 / 100$ & $\begin{array}{l}0.911 / 15 \\
(73 \%)\end{array}$ & \\
\hline
\end{tabular}

\footnotetext{
* Both before and during clonidine administration, patients were receiving a maximal daily dose of a diuretic agent, as defined in the text.

$t$ "None" in this and following tables indicates that no antihypertensive treatment other than a diuretic agent was being given on the day before the start of clonidine therapy. Most patients had been taking other antihypertensive agents in the preceding weeks.

$\ddagger+=$ blood pressure reduction in final month considered sig. nificant (see text). - not significant.

$G=$ guanethidine; $M=$ methyldopa (Aldomet); $R=$ reserpine.
} 


\begin{tabular}{|c|c|c|c|c|c|c|c|}
\hline \multirow{3}{*}{\multicolumn{2}{|c|}{$\begin{array}{l}\text { Prior Treatment } \\
\text { (daily dose, } \mathrm{mg} \text { ) }\end{array}$}} & \multicolumn{6}{|c|}{ Treatment with Clonidine } \\
\hline & & \multirow{2}{*}{$\begin{array}{c}\text { Initial } \\
\text { Recumbent } \\
\text { Blood Pressure } \\
(\mathrm{mm} \mathrm{Hg})\end{array}$} & \multicolumn{2}{|c|}{ 6th Month } & \multicolumn{3}{|c|}{ 12th Month } \\
\hline & & & $\begin{array}{l}\text { Recumbent } \\
\text { Blood Pressure } \\
\text { (mm Hg) }\end{array}$ & $\begin{array}{l}\text { Daily Dose } \\
\text { (mm Hg) }\end{array}$ & $\begin{array}{l}\text { Recumbent } \\
\text { Blood Pressure } \\
(\mathrm{mm} \mathrm{Hg})\end{array}$ & $\begin{array}{l}\text { Daily Dose } \\
\text { (mg) }\end{array}$ & $\begin{array}{l}\text { Blood } \\
\text { Pressure }\end{array}$ \\
\hline \multicolumn{2}{|c|}{ None } & $152 / 109$ & $140 / 100$ & 0.6 & $135 / 100$ & 0.3 & + \\
\hline \multicolumn{2}{|c|}{ None } & $166 / 117$ & $152 / 99$ & 0.6 & $154 / 100$ & 0.9 & + \\
\hline \multicolumn{2}{|c|}{ None } & $166 / 107$ & $117 / 91$ & 0.6 & 144/ 91 & 0.8 & + \\
\hline \multicolumn{2}{|c|}{ None } & $190 / 150$ & $177 / 124$ & 1.2 & $170 / 122$ & 1.6 & + \\
\hline & $500\}$ & $200 / 130$ & $224 / 144$ & 2.1 & $158 / 92$ & 2.8 & + \\
\hline \multicolumn{8}{|c|}{$\mathrm{R} \quad 2.5\}$} \\
\hline \multicolumn{2}{|c|}{ M 750} & $172 / 117$ & $141 / 99$ & 0.4 & $121 / 81$ & 0.4 & + \\
\hline & 1,000 & $190 / 120$ & $155 / 88$ & 0.4 & $139 / 88$ & 0.8 & + \\
\hline \multicolumn{2}{|c|}{ M 1,000} & $192 / 112$ & $187 / 96$ & 1.2 & $180 / 95$ & 1.2 & - \\
\hline \multicolumn{2}{|c|}{ G 25} & $180 / 126$ & $165 / 117$ & 1.2 & $162 / 114$ & 1.2 & - \\
\hline \multicolumn{2}{|c|}{ G 25} & $170 / 99$ & $124 / 81$ & 0.3 & $120 / 80$ & 0.3 & + \\
\hline \multicolumn{2}{|c|}{ G 30} & $196 / 113$ & $153 / 98$ & 1.2 & $142 / 93$ & 1.2 & + \\
\hline \multicolumn{2}{|c|}{ G 35} & $154 / 122$ & $140 / 100$ & 0.8 & $140 / 108$ & 0.8 & + \\
\hline \multirow{2}{*}{$\begin{array}{l}\mathbf{G} \\
\mathbf{G}\end{array}$} & 50 & $210 / 135$ & $165 / 102$ & 0.3 & $140 / 97$ & 0.5 & + \\
\hline & 50 & $180 / 130$ & $170 / 120$ & 2.4 & $202 / 120$ & 2.4 & - \\
\hline & $250\}$ & $240 / 130$ & $217 / 126$ & 1.6 & $204 / 137$ & 2.4 & - \\
\hline & $50\}$ & & & & & & \\
\hline & Average & $184 / 121$ & $162 / 106$ & 1.0 & $154 / 101$ & $\begin{array}{l}1.211 \\
(73 \%)\end{array}$ & \\
\hline
\end{tabular}

Braces indicate patients receiving more than 1 drug. Abbreviations as in Table II.

treat only those hypertensive patients taking guanethidine and a diuretic agent and experiencing severe postural falls in blood pressure. Later the study was enlarged to include patients with less severe forms of hypertension whose control of blood pressure with other drugs had proved unsatisfactory. To date our experience includes nearly 60 patients treated with a diuretic agent and clonidine and followed up for 6 months or more, most of them severely ill with various complications of hypertensive disease (azotemia in 19, prior stroke in 2 persons). Finally we chose to test the interrelation between clonidine and other antihypertensive drugs used in the treatment of hypertension.

All patients were seen in a morning hypertension clinic where casual standing, recumbent and 15-minute resting blood pressure measurements were taken in this sequence. The casual recumbent and standing values for blood pressure were used in the tables that follow.

\section{Results}

Confirmation of the long-term antihypertensive action of clonidine: Early in the study we wanted to assure ourselves that the decline in blood pressure was not a spontaneous result of prolonged control of blood pressure plus the psychosomatic influence of attending a carefully supervised clinic. Hence, some patients were asked to take for 12 to 24 hours a placebo medication made to resemble clonidine; the diuretic treatment was maintained. A rapid rise in blood pressure appeared, exceeding in many cases the original untreated level (Table I). The patients showed signs of a rebound over- activity of the sympathetic nervous system : tachycardia, tremulousness, overactivity and insomnia. A single dose of clonidine caused a dramatic remission in these symptoms.

Long-term effects of antihypertensive treatment with clonidine and a diuretic agent*: In the majority of cases it was found possible to control the blood pressure, even in the most severely hypertensive and azotemic patients. Clonidine was usually given initially in a dose of 0.1 to $0.2 \mathrm{mg} 3$ times daily in addition to the pre-existing regimen. When an effect on the blood pressure appeared, the prior therapy, except for the diuretic agent, was gradually discontinued. Increments of clonidine were then prescribed as the patient's side effects permitted. Drowsiness and dry mouth were the most frequent limitations; sometimes it was found helpful to add methylphenidate hydrochloride (Ritalin ${ }^{\circledR}$ ) to maintain greater alertness during these periods when the drug was being increased. However, when a satisfactory level of blood pressure control was finally stabilized, the side effects became relatively unimportant.

Tables II to V present the latest cumulative experience with 57 patients on long-term treatment,

* A thiazide diuretic agent was given in maximal dosage (in most cases chlorthalidone, $50 \mathrm{mg}$ daily). Aldactone, 25 $\mathrm{mg}$, plus hydrochlorothiazide, $25 \mathrm{mg}, 1$ tablet twice daily, was substituted when hypokalemia was a major chronic problem in patients on this regimen. All patients were receiving a noadded salt diet. 
HOOBLER AND SAGASTUME

TABLE IV

Initial and Final Effects of Clonidine in All Patients Followed Up 18 Months or More

\begin{tabular}{|c|c|c|c|c|c|c|c|}
\hline \multirow{3}{*}{\multicolumn{2}{|c|}{$\begin{array}{l}\text { Prior Treatment } \\
\text { (daily dose, } \mathrm{mg} \text { ) }\end{array}$}} & \multicolumn{6}{|c|}{ Treatment with Clonidine } \\
\hline & & \multirow{2}{*}{$\begin{array}{c}\text { Initial } \\
\text { Recumbent } \\
\text { Blood Pressure } \\
\text { (mm Hg) }\end{array}$} & \multicolumn{2}{|c|}{ 6th Month } & \multicolumn{3}{|c|}{ 18th Month } \\
\hline & & & $\begin{array}{c}\text { Recumbent } \\
\text { Blood Pressure } \\
\text { (mm Hg) }\end{array}$ & $\begin{array}{l}\text { Daily Dose } \\
\text { (mg) }\end{array}$ & $\begin{array}{c}\text { Recumbent } \\
\text { Blood Pressure } \\
(\mathrm{mm} \mathrm{Hg})\end{array}$ & $\begin{array}{l}\text { Daily Dose } \\
\text { (mg) }\end{array}$ & $\begin{array}{l}\text { Blood } \\
\text { Pressure }\end{array}$ \\
\hline \multicolumn{2}{|c|}{ None } & $235 / 150$ & $180 / 130$ & 1.2 & $191 / 124$ & 2.0 & + \\
\hline \multicolumn{2}{|c|}{ None } & $142 / 94$ & $145 / 100$ & 0.4 & $130 / 89$ & 0.4 & - \\
\hline \multicolumn{2}{|c|}{ None } & $161 / 113$ & $150 / 95$ & 0.3 & $171 / 105$ & 0.4 & - \\
\hline \multicolumn{2}{|c|}{ None } & $179 / 119$ & $150 / 108$ & 0.8 & $125 / 93$ & 0.4 & + \\
\hline \multicolumn{2}{|c|}{ None } & $260 / 160$ & $190 / 120$ & 0.7 & $177 / 78$ & 1.6 & + \\
\hline & 500 & $260 / 190$ & $270 / 150$ & 2.0 & $247 / 150$ & 2.4 & - \\
\hline & 750 & $175 / 122$ & $144 / 100$ & 0.6 & $136 / 95$ & 0.3 & + \\
\hline & 1,000 & $175 / 132$ & $134 / 104$ & 0.6 & $165 / 116$ & 0.6 & - \\
\hline & 1,500 & $164 / 119$ & $140 / 95$ & 0.3 & $137 / 99$ & 0.3 & + \\
\hline & 2,000 & $190 / 110$ & $272 / 156$ & 1.6 & $165 / 103$ & 2.0 & - \\
\hline \multicolumn{7}{|c|}{ G 12.5$\}$} & + \\
\hline \multirow{2}{*}{\multicolumn{8}{|c|}{$\begin{array}{ll}\text { G } & 50 \\
M & 750\}\end{array}$}} \\
\hline \multicolumn{7}{|c|}{ G 50$\}$} & \\
\hline \multicolumn{8}{|c|}{$\left.\begin{array}{ll}M & 750 \\
G & 62.5\end{array}\right\}$} \\
\hline \multirow{2}{*}{\multicolumn{2}{|c|}{ Average }} & $204 / 118$ & $184 / 116$ & 0.9 & $150 / 95$ & 1.2 & + \\
\hline & & $198 / 129$ & $180 / 115$ & 0.9 & $164 / 107$ & $\begin{array}{l}1.18 / 15 \\
(53 \%)\end{array}$ & \\
\hline
\end{tabular}

Abbreviations as in Table II.

\section{TABLE V}

Initial and Final Effects of Clonidine in All Patients Followed Up 24 Months or More

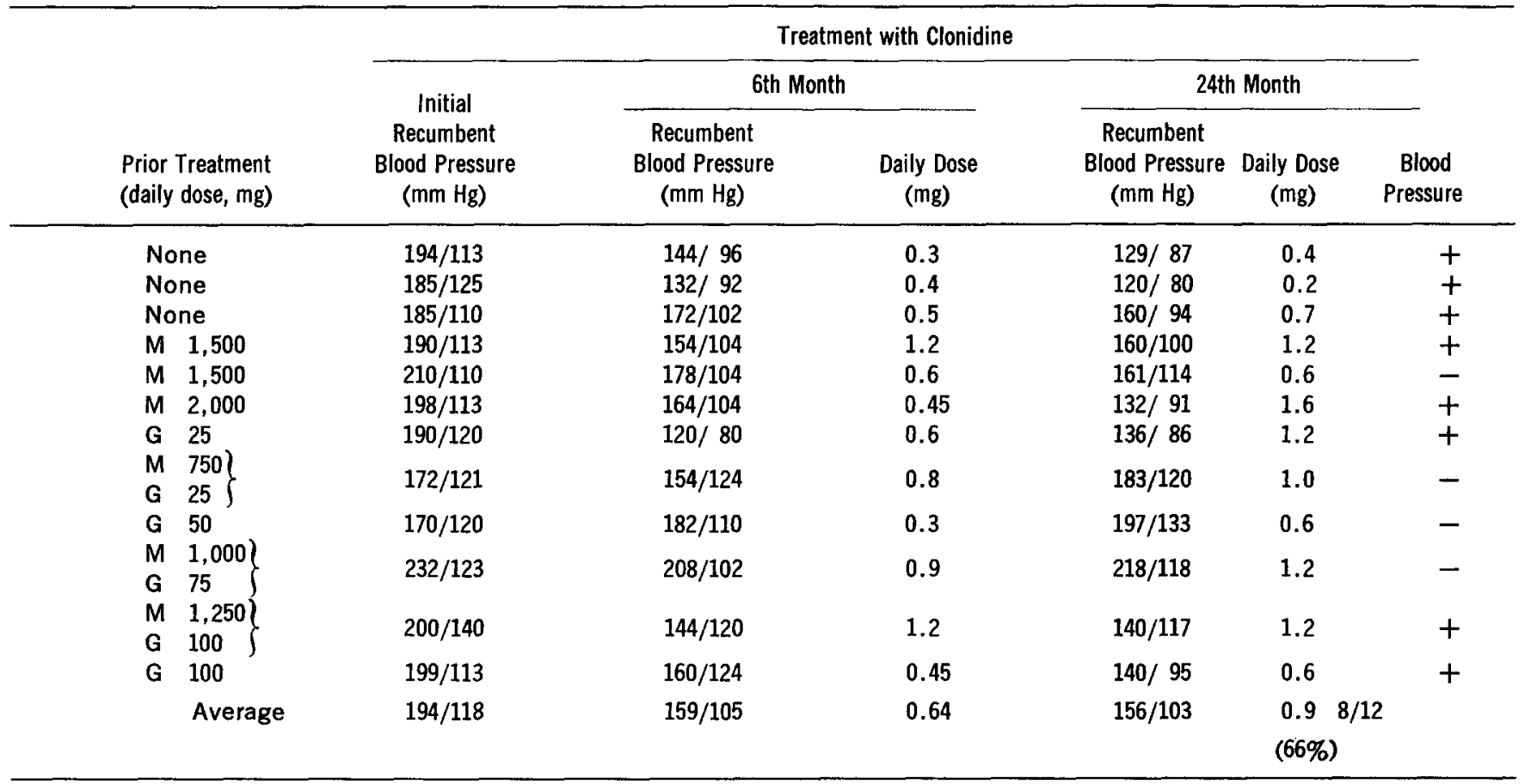

Abbreviations as in Table II. 


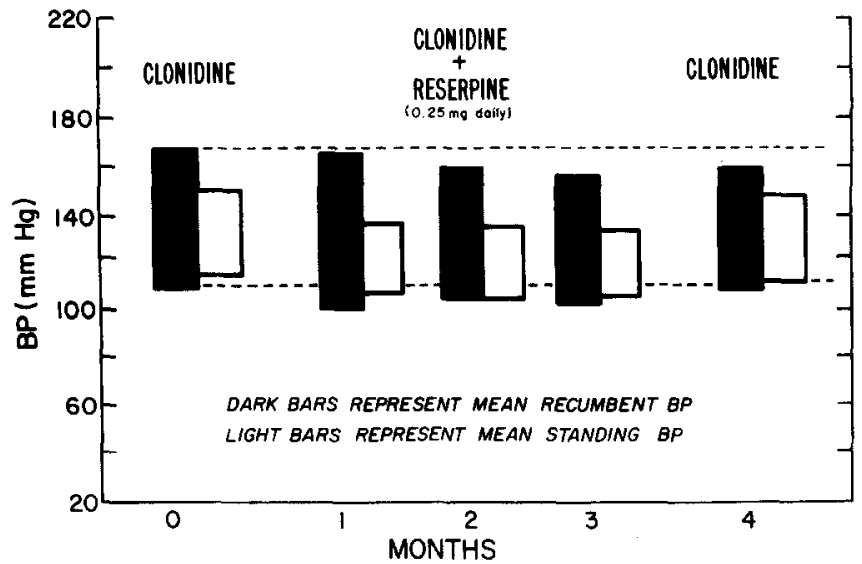

Figure 1. Addition of reserpine to clonidine (middle 3 bars) in 10 cases resulted in a slight decrease in blood pressure compared to control periods (first and last pair of bars).

and compare values for blood pressure with those obtained under similar clinic circumstances before administration of clonidine. Blood pressure was considered significantly lowered by clonidine compared with other prior treatment regimens when there was a reduction of $15 \mathrm{~mm}$ in the systolic and $10 \mathrm{~mm}$ in the diastolic blood pressure.

The following conclusions may be drawn. There was no loss in drug effectiveness with the passage of time since the average reduction in blood pressure and dose of drug remained about the same in the sixth and in the final months of treatment. The severity of the original hypertension did not alter the overall success rate (about 66 percent).

Of 25 patients with hypertension severe enough to require guanethidine originally, 15 showed improvement on a regimen of clonidine, an overall 60 percent favorable effect. These patients had been frequently disabled by orthostatic hypotension; this was rarely a problem with the new drug.

The blood pressure of 7 of 12 patients ( 58 percent) previously taking methyldopa in a daily dosage of $1,000 \mathrm{mg}$ or more was more successfully managed with administration of clonidine.

Most impressive of all was the response of the patients with milder hypertension, those taking reserpine and those in whom it was considered safe to omit the prior treatment for a few days before starting treatment with clonidine. Twelve of 14 were judged to have had a significant reduction of blood pressure on a regimen of clonidine and a diuretic agent.

Combination of clonidine and other antihypertensive agents: Over a 3-month period the dose of clonidine was held constant, and a standard increasing dose of another drug was added. At the beginning of the interaction study, 2 blood pressure readings were recorded at 2 intervals 1 month apart while the patient was taking clonidine and a diuretic agent plus a placebo resembling the drug to be supplied. The average of these readings

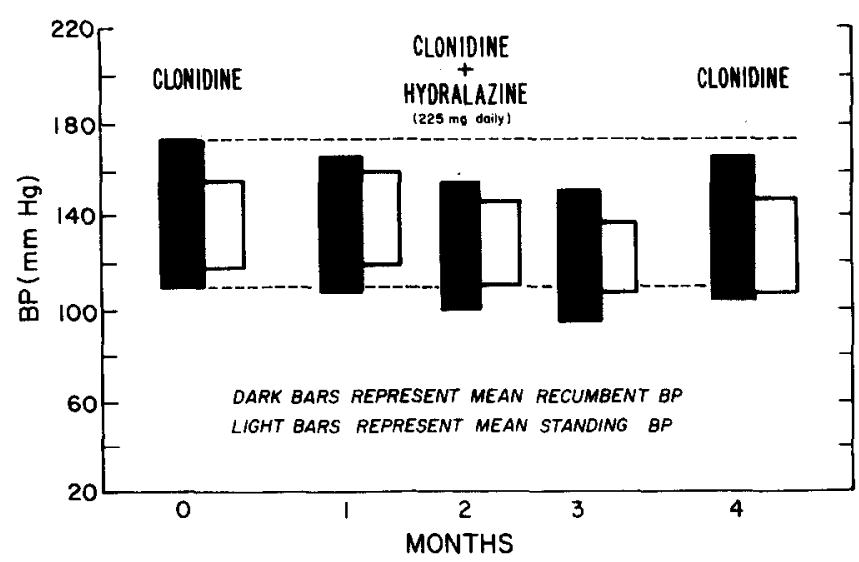

Figure 2. Addition of hydralazine to clonidine in progressively increasing doses ( 75,150 and $225 \mathrm{mg}$ daily) in 10 cases resulted in further declines in the blood pressure.

was considered the base line value. The patient then received active drug instead of placebo for 3 months. The placebo then replaced the active drug for a final month.

In 10 patients reserpine, $0.25 \mathrm{mg}$ daily, was given for the entire 3 month period. In 10 other subjects hydralazine was administered, increasing each month from 25 to 50 to $75 \mathrm{mg} 3$ times daily. Ten patients were also given alpha-methyldopa, $250 \mathrm{mg} 3$ times daily, for the first month and 500 $\mathrm{mg}$ twice daily for the remaining 2 months. (Fig. 1 to 3). With hydralazine and reserpine a slight additive effect was seen and confirmed by a small increase in blood pressure during the subsequent administration of placebo. With methyldopa no added effect on blood pressure was observed. Side effects were similar to those usually seen with clonidine and with the added antihypertensive agent.

Studies on the additive effect of guanethidine were carried out differently, owing to the slow

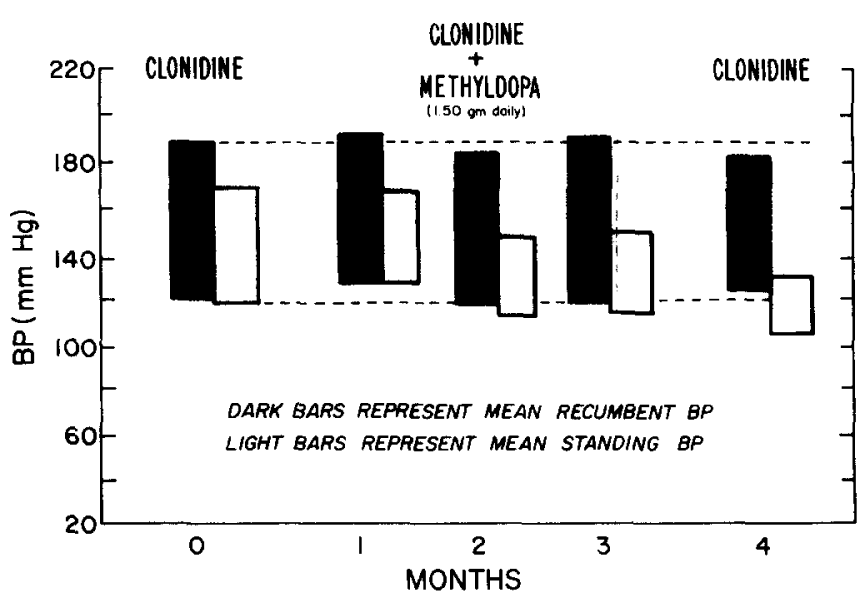

Figure 3. Addition of alpha-methyldopa to clonidine (750, 1,000 and $1,500 \mathrm{mg}$ in successive months) in 10 cases produced no further decline in values for recumbent blood pres. sure but did result in some decline in those for standing blood pressure. 


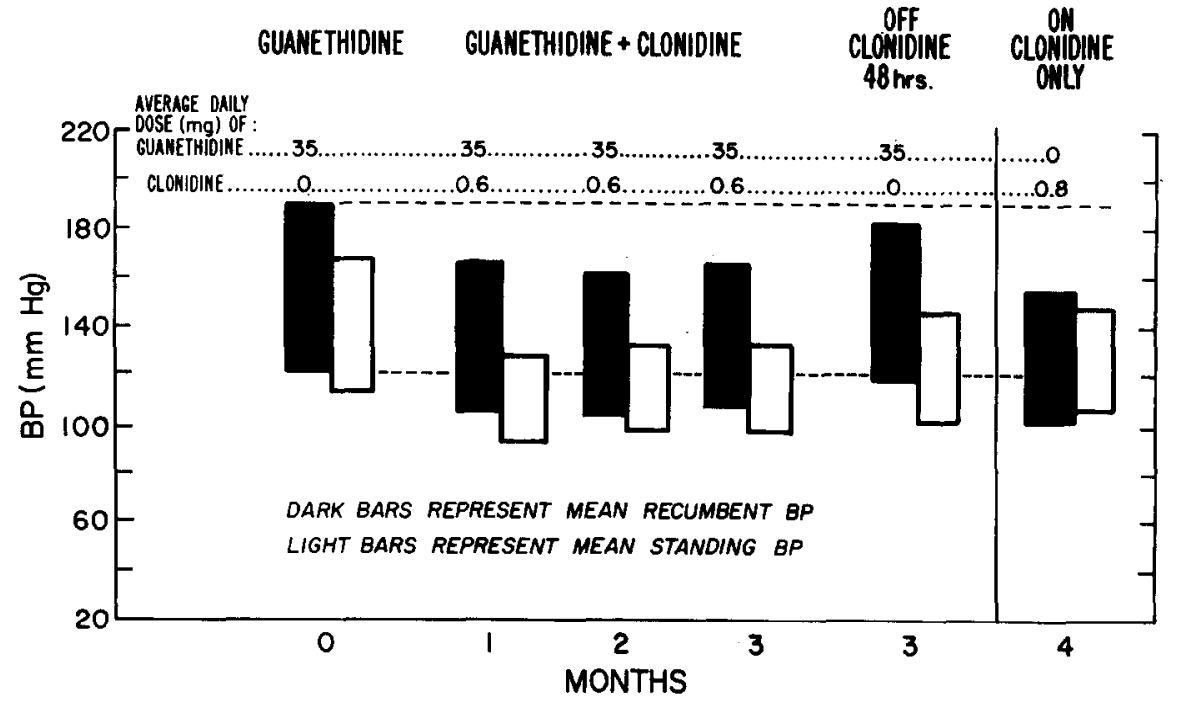

Figure 4. Combined therapy with guanethidine and clonidine in 10 cases. When the latter drug was added (second, third and fourth pairs of bars) a reduction in both recumbent and standing blood pressure levels was observed. When placebo was substituted, these blood pressure levels rose (fifth pair of bars). More satisfactory control of blood pressure was achieved with clonidine alone (pair of bars at extreme right). offset of action seen when this adrenergic blocking agent is withdrawn. The blood pressure of 10 patients was recorded at 2 intervals 1 month apart while they were receiving a fixed dose of guanethidine to which a placebo resembling clonidine had been added. The placebo was then replaced by clonidine, ( $0.2 \mathrm{mg} 3$ times daily), for the ensuing 3 months. At the end of this period the patient was hospitalized, and a placebo to replace clonidine was substituted for 48 hours. The patients were then discharged with an increased dose of clonidine while the guanethidine was omitted. Their blood pressure 1 month later was recorded. The results (Fig. 4) show that clonidine added to guanethidine decreased both the standing and recumbent values for blood pressure. The orthostatic gradient was slightly increased. These effects were reversed by withdrawal of clonidine. When the guanethidine had been totally replaced by clonidine, the recumbent blood pressure 1 month later was lower than during administration of guanethidine and showed a lesser orthostatic gradient.

Effect on the vascular complications of hypertension: The majority of patients had severe hypertension ard many complications of this disease. Azotemia was the most common, serum creatinine levels being elevated before institution of clonidine therapy in 19 individuals (range 2.2 to $8.9 / 100$ $\mathrm{ml})$. Over a mean time interval of 15 months worsening of azotemia was seen only in 1 patient (creatinine increased from 4.7 to 6.1 in 15 months).

Two patients had previously had strokes. One of these, whose blood pressure control on a regimen of clonidine was difficult, had 2 ischemic strokes and died after 2 years of treatment. The other patient did not experience a recurrence in 38 months. Two patients, both with apparently well controlled hypertension, had transient ischemic attacks while receiving clonidine therapy. These attacks were presumed, after arteriography, to have been caused by extracranial occlusive disease. One patient, who was in the phase of malignant hypertension when started on treatment and had had good control, experienced a late increase in blood pressure which was accompanied by an attack of hemiplegia.

There were 2 myocardial infarctions during the period of observation. Both were well tolerated. Treatment with clonidine was not interrupted. One case of aortic aneurysm appeared in a patient whose blood pressure control during therapy had been erratic.

Side effects and toxicity: At the end of 1 year most patients were given the chance to return to their previous antihypertensive regimen. None preferred to do this; dry mouth, transitory sleepiness and constipation, while present, were far less incapacitating than at first. Potency was usually retained in the male subjects; episodes of orthostatic syncope were quite rare. Meanwhile, tests of hemoglobin, white blood cell count, urine, blood urea nitrogen, creatinine, uric acid and sugar taken at 3 month intervals showed no changes. Liver function was not impaired according to the serum glutamic pyruvic transaminase test. Jaundice was not seen; occasional rashes were traced to other concomitant medication. A special search for retinal lesions, reported to occur in some rats taking clonidine in chronic toxicity studies, had entirely negative results. The drug often produced profound bradycardia and sleepiness in overdosage, but there was no sign of cardiac dysrhythmia or stupor. We are convinced of the remarkable safety and long-term effectiveness of clonidine.

\section{Acknowledgments}

We are indebted to Miss Alice Warsinski, RN, and Mrs. Ralph Oesterle, RN, and to Mrs. Ned Jorgensen for their careful work in recording and compiling the data on which this report is based. 


\section{References}

1. Kobinger W: Uber den Wirkungsmechanismus einer neuen antihypertensiven Substanz mit Imidazolinstruktur. Naunyn Schmiedeberg Arch Pharm Exp Path 258:48-58, 1967

2. Sattler RW, Van Zwieten PA: Acute hypotensive action of 2-(2,6-dichlorophenylamino)-2-imidazoline hydrochloride (ST 155) after infusion into the cat's vertebral artery. Europ J Pharmacol 2:9-13, 1967

3. Schmitt H, Schmitt N, Boissier JR, et al: Centrally mediated decrease in sympathetic tone induced by $2(2,6-\mathrm{di}$ chlorophenylamino)-2-imidazoline (ST 155, catapresan). Europ J Pharmacol 2:147-148, 1967

4. Onesti G, Schwartz AB, Kim KE, et al: Pharmacodynamic effects of a new antihypertensive drug, catapres, (ST-155). Circulation 39:219-228, 1969
5. Merguet $\mathbf{P}$, Heimsoth V, Murata $T$, et al: Experimental study of the circulatory effects of 2-(2,6-dichlorophenylamine)-2-imidazoline hydrochloride in man. Pharmacol Clin 1:30-37, 1968

6. Naylor WG, Rosenbaum M, McInnes $I$, et al: Effect of a new hypotensive drug, ST 155, on the systemic circula. tion. Amer Heart J 72:764-770, 1966

7. Constantine JW, McShane WK: Analysis of the cardiovascular effects of 2-(2,6-dichlorophenylamino)-2-imidazoline hydrochloride (catapres). Europ J Pharmacol 4:109123,1968

8. Smet G, Hoobler SW, Sanbar S, et al: Clinical observations on a new antihypertensive drug, 2-(2,6-dichlorphenylamine)-2-imidazoline hydrochloride. Amer Heart J 77: $473-478,1969$ 